\title{
Oxidative stress evaluation of ischemia and reperfusion in kidneys under various degrees of hypothermia in rats $^{1}$
}

\author{
Emanuel Burck dos Santos ${ }^{I}$, Walter José Koff ${ }^{1 I}$, Tomaz de Jesus Maria Grezzana Filho"II, Samanta Daiana De Rossi ${ }^{\text {IV }}$, Lisiane \\ Treis $^{\mathrm{IV}}$, Silvia Regina Bonav, Karla Laís Pêgas ${ }^{\mathrm{VI}}$, Betina Katz ${ }^{\mathrm{VII}}$, Fabíola Schons Meyer ${ }^{\mathrm{VIII}}$, Norma Anair Possa Marroni ${ }^{\mathrm{IX}}$, Carlos \\ Otávio Corso ${ }^{\mathrm{x}}$
}

\begin{abstract}
IMSc, PhD, Physician, Division of Urology, Porto Alegre Clinics Hospital, Brazil. Conception and design of the study, surgical procedures, acquisition, interpretation and analysis of data, manuscript writing.

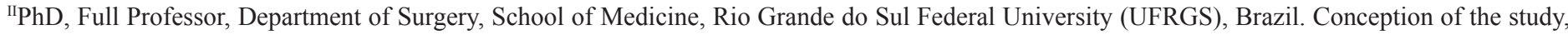
critical revision.

IIIMSc, PhD, Physician, Division of Surgery, Porto Alegre Clinics Hospital, Brazil. Conception of the study, technical procedures.

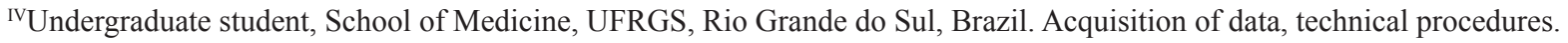

${ }^{v}$ MSc, Fellow PhD degree, Postgraduate Program in Genetics and Applied Toxicology, Brazilian Lutheran University (ULBRA). Biologist, Department of Physiology, School of Medicine, UFRGS, Rio Grande do Sul, Brazil. Acquisition and interpretation of data, technical procedures.

${ }^{\mathrm{V}} \mathrm{MSc}$, Physician, Department of Pathology, Porto Alegre Clinics Hospital, Brazil. Histopathological examinations, acquisition of data.

${ }^{\mathrm{VII}} \mathrm{MD}$, Resident, Department of Pathology, Porto Alegre Clinics Hospital, Brazil. Histopathological examinations, acquisition of data.

VIIIMSc, Veterinarian, Experimental Research Center (CPE), Porto Alegre Clinics Hospital, Brazil. Anesthesia, technical procedures.

${ }^{\mathrm{Ix}} \mathrm{MSc}$, PhD, Full Professor, Department of Physiology. Chief of the Laboratory of Experimental Research in Hepatology, UFRGS, Rio Grande do Sul, Brazil. Acquisition and interpretation of data, technical procedures.

${ }^{\mathrm{x}} \mathrm{MSc}, \mathrm{PhD}$, Associate Professor, Department of Surgery, School of Medicine, UFRGS, Rio Grande do Sul, Brazil. Conception and design of the study, interpretation of data, manuscript writing, critical revision.
\end{abstract}

\section{ABSTRACT}

PURPOSE: To design an animal model of ischemia-reperfusion (I/R) in kidneys and evaluate the role that predetermined ranges of local hypothermia plays on markers of stress-oxydative as well as on histologic sections.

METHODS: Twenty eight male rats Wistar, under general anesthesia, undergone right nephrectomy (G0, control group) followed by left kidney ischemia during $40 \mathrm{~min}$. Four temperatures groups were designed, with seven animals randomized for each group: normothermic $\left(\mathrm{G} 1, \pm 37^{\circ} \mathrm{C}\right)$, mild hypothermia $\left(\mathrm{G} 2,26^{\circ} \mathrm{C}\right)$, moderate hypothermia $\left(\mathrm{G} 3,15^{\circ} \mathrm{C}\right)$ and deep hypothermia $\left(\mathrm{G} 4,4^{\circ} \mathrm{C}\right)$. Left kidney temperature was assessed with an intraparenchymal probe. Left nephrectomy was performed after $240 \mathrm{~min}$ of reperfusion. After I/R a blood sample was obtained for f2-IP. Half of each kidney was sent to pathological evaluation and half to analyze CAT, SOD, TBARS, $\mathrm{NO}_{3}, \mathrm{NO}_{2}$.

RESULTS: Histopathology showed that all kidneys under I/R were significantly more injured than the G0 ( $<<0.001)$. TBARS had increased levels in all I/R groups compared with the G0 $(p<0.001)$. CAT had a significant difference $(p<0.03)$ between $G 1$ and G4. Finally, no difference was found on $\mathrm{SOD}, \mathrm{NO}_{3}, \mathrm{NO}_{2}$ nor on f2-IP.

CONCLUSION: This model of I/R was efficient to produce oxidative-stress in the kidney, showing that $4^{\circ} \mathrm{C}$ offered significant decrease in free radicals production, although tissue protection was not observed.

Key words: Hypothermia. Ischemia. Reperfusion. Kidney. Oxidative Stress. Lipid Peroxidation. Rats 


\section{Introduction}

In transplants is widely accepted that hypothermia is protective against injury caused by ischemia and reperfusion $(\mathrm{I} / \mathrm{R})^{1}$. Even though the preconized temperature to obtain preservation is around $4^{\circ} \mathrm{C}$, there are evidences that much higher temperatures, $26^{\circ} \mathrm{C}$ or even $34^{\circ} \mathrm{C}$, are enough to achieve liver protection without necessity of deeper hypothermia ${ }^{2,3}$. It is known that is easier to obtain mild or moderate cooling, and that deep hypothermia is more associated with thermal injury of tissue. Also, it is important to mention that slight hypothermia has a lesser interference in the systemic temperature ${ }^{4}$. Although the demonstration that mild hypothermia is sufficient to offer liver protection against the deleterious actions of $\mathrm{I} / \mathrm{R}$, there are no studies concerning the kidney ${ }^{2,3}$.

The main target regarding the $\mathrm{I} / \mathrm{R}$ renal damage is the proximal convoluted tubule, with relative glomerular preservation $^{5,6}$. The intensity of necrosis is related to the ischemic time. The recovery of acute tubular necrosis starts in two days from the $\mathrm{I} / \mathrm{R}^{5}$. The longer the cold storage is, the greater the changes on sodium-potassium adenosine triphosphate $(\mathrm{Na} / \mathrm{K}-\mathrm{ATP})$ and in the proteins cytoskeleton, such as ezrin. All these events cause timedependent lipid membranes injury, disorganizing the nephron tubular function during the cold storage, contributing with the damage that occurs during rewarming ${ }^{7}$. Cold storage induces cell death due to the appearance of iron-dependent reactive oxygen species, with apoptosis in the rewarming period. Even without ischemia, the lesion induced by hypothermia occurs regardless the kind of preservation solution used ${ }^{8}$.

Lipid peroxidation is a consequence from the reaction between free radicals and lipid membranes of the cells and mitochondria ${ }^{9}$. It is known that hypothermia is associated to protection against $\mathrm{I} / \mathrm{R}$ injury ${ }^{1}$, however there is not any experimental systematic study in vivo that demonstrate what range of temperature protects kidney, although this information has already been available for the liver ${ }^{2,3}$. That gap of information is important because is relevant know how much cooling is necessary to achieve renal protection without causing hypothermic damage $^{8,10}$.

\section{Methods}

In order to evaluate the role played by free radicals, indirect markers are usually searched ${ }^{11-14}$, because it is difficult to perform straight assessment of such unstable reactive species ${ }^{15}$. The antioxidant activity is measured through enzymes as superoxide dismutase (SOD) and catalase (CAT). Besides the enzymes, the lipid peroxidation may be evaluated through thiobarbituric acid reactive species (TBARS) determination. SOD, CAT and TBARS are evaluated from tissues samples. To systemic assessment, f2isoprostanes (F2IP) from plasma can be useful to observe lipid peroxidation. Nitrites $\left(\mathrm{NO}_{2}\right)$ and nitrates $\left(\mathrm{NO}_{3}\right)$ from tissue are useful to evaluate nitric oxide (NO) metabolism ${ }^{16}$. Qualitative analyze of renal tissue is obtained from histopathological examination ${ }^{5}$.

\section{Animals, anesthesia and surgical procedure}

The study received approbation of the Animal Research Ethical Committee (Research and Post-Graduation Group, Porto Alegre Clinics Hospital) according to the Good Animal Practice guidelines (Guide for the Care and Use of Laboratory Animals, National Institute of Health, Bethesda, US, 2011).

Twenty eight males Wistar adult rats, weighting between $240 \mathrm{~g}$ and $487 \mathrm{~g}$, were kept in cages with free access to water and feed. The cages were acclimatized, including light and noise control. The cages with the animals were kept in the Animal Experimentation Center (Porto Alegre Clinics Hospital). The rats were weighted and underwent general anesthesia with intraperitoneal administration of ketamine $(75 \mathrm{mg} / \mathrm{Kg})$ and xylazine $(10 \mathrm{mg} / \mathrm{Kg})$. Rear paw reflexes were tested to ensure that full general anesthesia was achieved. The animal was put in a warm surgical table $\left(37^{\circ} \mathrm{C}\right)$ and oxygen $(1 \mathrm{~L} / \mathrm{min})$ was administrated through campanula. Before abdominal incision, bupivacaine $0.5 \%$ was injected in the abdominal wall to ensure pain control during and after the procedure. A longitudinal median incision was made, and surgical retractors were applied. Right nephrectomy was performed. Half of the right kidney was sent in formalin to histopathological examination, and the other half in liquid nitrogen to $-80^{\circ} \mathrm{C}$ freezer. Afterwards the left kidney had his vessels clamped for 40 minutes (ischemia). The left kidney was isolated from the rest of the abdominal cavity through the application of a specially designed device made of latex and polystyrene. The left kidney target-temperature was achieved through superfusion of iced saline solution and kept during all the time of ischemia (40 minutes) (Figure 1). After this time, the renal pedicle was unclamped (start of the warm reperfusion) and abdominal wall was closed. The animal was moved to a warmed new cage, with water, but without food. After 240 minutes of reperfusion, the rat was moved from the cage to the surgical table. New anesthesia was done with the same doses of ketamine and xylazine, but this time the way of administration adopted was intra-muscular instead 
of intra-peritoneal to avoid the previous violation of the peritoneal cavity. The abdominal wall sutures were removed and left nephrectomy was done. The same procedures applied to the right kidney were made for the left one. Blood sample was collected through heart puncture. Cardiectomy was performed to ensure the animal death still under anesthesia.

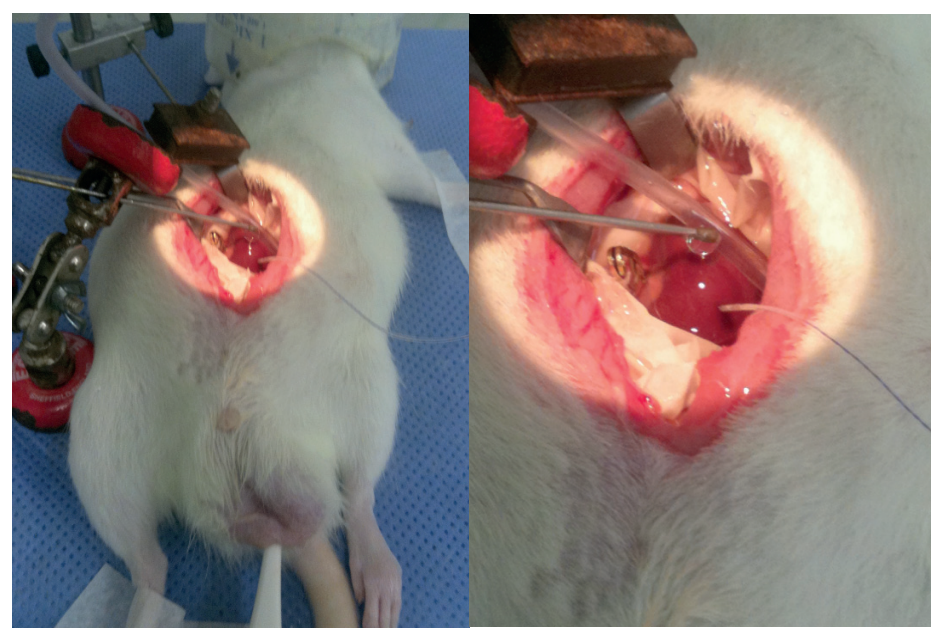

FIGURE 1 - Left kidney under ischemia and local hypothermia.

\section{Adjustment of left kidney temperature}

During the 40 minutes of ischemia, the cortical left kidney temperature was assessed with an intra-parenchymal probe connected to a specific thermometer (BAT 12, IITC Life Science, W.Hills, CA, US). The microprobe was inserted short before of the placement of the vascular clamp. To avoid systemic hypothermia (groups G2, G3 and G4) the left kidney was carefully placed on a specially designed concaved-shaped polystyrene well and a vacuum device was connected inside the well to aspirate the solution used to cool down the kidney. To keep the normal systemic temperature, the animal was warmed with blankets. The surgical table was electrically warmed. For systemic temperature measurement it was applied a common electronic rectal thermometer (Termomed 1.0, ref. 29832, Incoterm, Brazil) $)^{2,17-19}$.

\section{Experimental protocol}

The effects of $\mathrm{I} / \mathrm{R}(40 \mathrm{~min} / 240 \mathrm{~min})$ on markers of lipid peroxidation were evaluated in four groups: Group 1, I/R without cooling $\left(\mathrm{G} 1,37^{\circ} \mathrm{C}\right)$; group $2, \mathrm{I} / \mathrm{R}$ with mild renal hypothermia $(\mathrm{G} 2$, $\left.26^{\circ} \mathrm{C}\right)$; group $3, \mathrm{I} / \mathrm{R}$ with moderate renal hypothermia $\left(\mathrm{G} 3,15^{\circ} \mathrm{C}\right)$; group 4, deep renal hypothermia $\left(\mathrm{G} 4,4^{\circ} \mathrm{C}\right)$. For statistical purposes, the right kidneys of all animals in all groups were considered as the group 0 (G0, control group, without I/R). In each group there were seven rats, i.e., a total of 28 animal providing control kidneys for the experiment.

\section{Assessment of the lipid peroxidation markers}

For SOD it was employed a method based on inhibition of the adrenochrome through the autoxidation of adrenaline by the $\mathrm{SOD}^{20}$. The change on the absorbance spectrophotometric of the adrenaline has indicated SOD. The CAT activity was assessed by the velocity of peroxide decomposition in water and oxygen through the peroxide absorbance measured by spectrometry. For TBARS it was made a measure of the malondialdehyde (MDA) absorbance by spectrometer on the presence of thiobarbituric acid. The quantification of proteins was obtained by the Lowry method. For plasmatic F2-IP it was performed an evaluation through the ALX-850-205-KI01 8-iso Prostaglandin F2-alpha EIA kit (F2isoprostanos; Enzo Life Sciences International, Inc., US). Nitrate reductase associated with NADPH cofactor, TrisBuffer, glucose6-phosphate and also glucose-6-phosphate-dehydrogenase were used to measure $\mathrm{NO}_{2}$ and $\mathrm{NO}_{3}$.

\section{Histopathology}

Half of each kidney was fixed in formalin, included in paraffin, cut in slides and colored with hematoxylin and eosin. The criteria employed to classify the findings were an adaptation of the work of Jablonski et al..$^{5}$. According to these authors, there are four grades of lesion: 1. Mitosis and necrosis of individual cells; 2. Necrosis of all cells in adjacent proximal convoluted tubules, with survival of surrounding tubules; 3 . Necrosis confined to the distal third of the proximal convoluted tubule with a band of necrosis extending across the inner cortex; 4 . Necrosis affecting all three segments of the proximal convoluted tubule. We created the grade zero to designate normal findings.

\section{Statistical analysis}

Data are presented as means \pm standard deviation. For the variables with normal distribution it was used one-way ANOVA. Bonferroni post-test was employed to analyze the differences among the means. The non-parametric test Kruskall-Wallis was used to the histology findings. $\mathrm{p}<0.05$ were considered significant. 


\section{Results}

\section{Histopathology}

There was no evidence of any kind of lesion in control group (right kidney, G0, without I/R), but all remaining groups showed variable levels of damage, regardless if under hypothermia (G2, G3, G4) or not (G1). Examining the three hypothermic groups no difference was found among them, taken into account the grade of lesions (1 to 4). The average grade of injury on G0 was zero. On the remaining groups, the respective means and standard

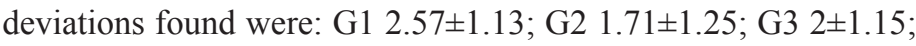
G4 2.57 \pm 1.13 . The difference between the G0 and all ischemic groups (G1 to $\mathrm{G} 4)$ had a $\mathrm{p}$ value $=0.005(\mathrm{G} 0 \mathrm{xG} 2)$ and $\mathrm{p}<0.001$ (G0xG1; G0xG3; G0xG4) (Figure 2).

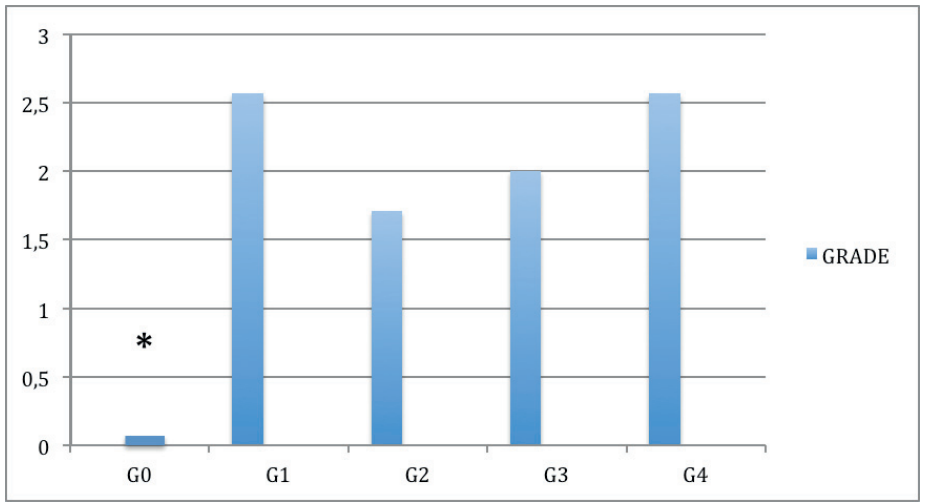

FIGURE 2 - Results of histological analysis. ${ }^{*} \mathrm{p}<0.001$ between G0 and all the other groups. No statistically significant difference was founded among the groups under $\mathrm{I} / \mathrm{R}$.

TBARS (thiobarbituric acid reactive species): It was found a statistically significant difference between the control group (G0) and all the I/R groups (G1-G4), regardless the renal target-temperature. The respective means and standard deviation were: G0 1.31 \pm 0.05 ; G1 1.67 \pm 0.07 ; G2 1.85 \pm 0.13 ; G3 2.05 \pm 0.20 ; G4 $1.95 \pm 0.13$. The units of the above means were expressed in nmol/mg of protein. $P<0.004 \mathrm{G} 0 \mathrm{x}$ I/R groups. (Figure 3 )

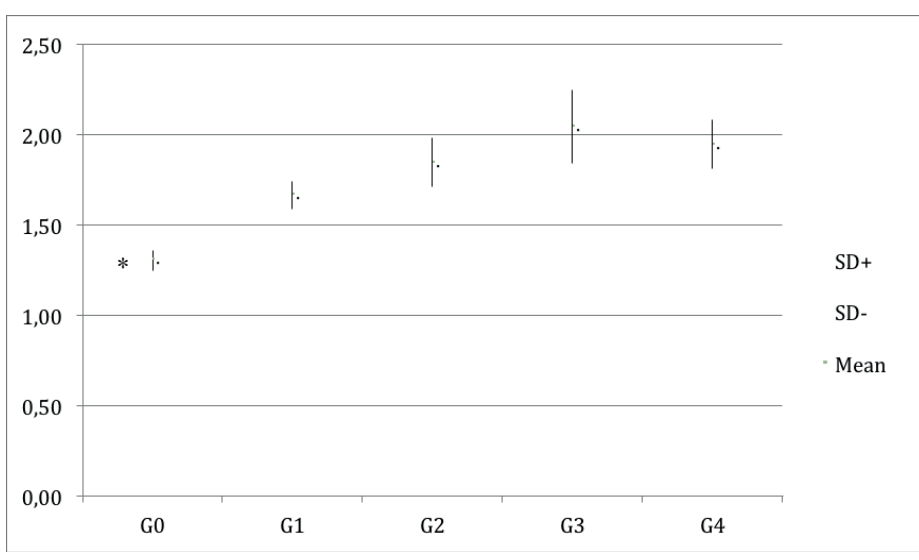

FIGURE 3 - Results of TBARS assay (left kidneys). G0 had significantly lower values than the other groups. No difference between groups subjected to ischemia $(* \mathrm{p}<0.001)$.

\section{$C A T$ (catalase)}

It was found a statistically significant difference between the most hypothermic group $\left(\mathrm{G} 4,4^{\circ} \mathrm{C}\right)$ and the normothermic group $\left(\mathrm{G} 1,37^{\circ} \mathrm{C}\right)$. The mean found to catalase was expressed in $\mathrm{pmol} / \mathrm{mg}$ of protein. Means and standard deviations observed were: $(\mathrm{G} 1=$ $2.32 \pm 0.30) \times(\mathrm{G} 4=1.03 \pm 0.30)$, with a $\mathrm{p}=0.03(\mathrm{G} 1 \mathrm{xG} 4) ;(\mathrm{G} 0=$ $1.95 \pm 0.01)$, with a $\mathrm{p}=0.08(\mathrm{G} 0 \mathrm{xG} 4)$. The remaining comparisons among the groups had no difference with statistic significance. $\left(\mathrm{G} 0=1.954 \rightarrow \mathrm{G} 1=2.323^{*} \rightarrow \mathrm{G} 2=1.282 \rightarrow \mathrm{G} 3=1.179 \rightarrow \mathrm{G} 4\right.$ $=1.038 * \mathrm{pmol} / \mathrm{mg}$ of protein). $* \mathrm{p}=0.03$ (Figure 4 ).

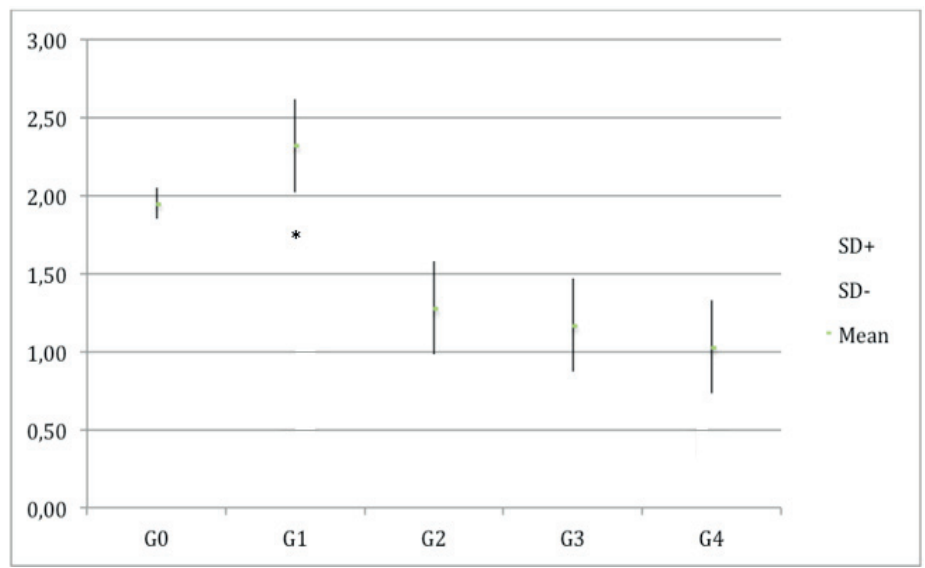

FIGURE 4 - Results of CAT assay. G1 $\left(37^{\circ} \mathrm{C}\right)$ had a value significantly greater than $\mathrm{G} 4\left(4^{\circ} \mathrm{C}\right) .{ }^{*} \mathrm{p}=0.03 . \mathrm{SD}=$ Standard Deviation, $\mathrm{M}=$ Mean, $\mathrm{G}=$ Group.

\section{SOD (superoxide dismutase)}

The results showed no difference among groups. The respective means and standard deviations observed were: G0

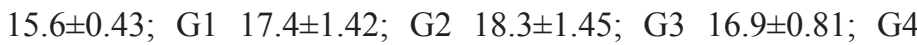
$15.7 \pm 0.95$. The units of the above means were expressed in $U$ $\mathrm{SOD} / \mathrm{mg}$ of protein. 


\section{$\mathrm{NO}_{2}$ and $\mathrm{NO}_{3}$ (nitrites and nitrates)}

No significant difference was found among the five groups for $\mathrm{NO}_{2}$ as well as $\mathrm{NO}_{3}$. The means and standard deviations observed for $\mathrm{NO}_{2}$ and $\mathrm{NO}_{3}$ respectively were: $\mathrm{G} 0 \quad 0.83 \pm 0.00$ and $2.07 \pm 0.17 ;$ G1 $0.07 \pm 0.00$ and $2.11 \pm 0.28 ; G 2 \quad 0.08 \pm 0.00$ and $2.89 \pm 0.25 ; \mathrm{G} 3 \quad 0.79 \pm 0.00$ and $2.36 \pm 0.32 ; \mathrm{G} 4 \quad 0.07 \pm 0.01$ and $2.054 \pm 0.270$. The units of the above means were expressed in $\mu \mathrm{mol} / \mathrm{L}$.

\section{Protein}

No significant difference was found among the five groups. The respective means and standard deviations observed were: G0 6.65 \pm 0.07 ; G1 6.07 \pm 0.28 ; G2 6.09 \pm 0.37 ; G3 6.84 \pm 0.26 ; G4 6.99 \pm 0.23 . The units of the above means were expressed in $\mathrm{mg} / \mathrm{mL}$.

\section{F2IP (F2-Isoprostanes)}

It was measured on plasma instead of the renal tissue. No significant difference was found among the four experimental groups. The respective means and standard deviation observed

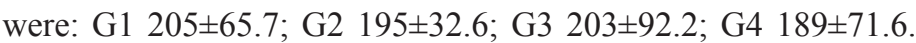
The units of the above means were expressed in $\mathrm{pg} / \mathrm{mL}$.

\section{Discussion}

The results presented above show interesting aspects about what happened on the adult Wistar rats' kidneys after 40 minutes of ischemia followed by 240 minutes of reperfusion. According to Jablonski et al. ${ }^{5}, 30$ minutes of warm ischemia are enough to induce changes on the proximal convoluted tubules from rats' kidneys. After 60 minutes of warm ischemia there is severe tubular necrosis. As expected, normal findings were found in all animals. Nonetheless, all animals underwent ischemia, regardless the target-temperature, showed changes when compared to the controls. Although any statistical significance had not occurred between the I/R normothermic group (G1) and the I/R hypothermic groups (G2-G4), it was observed a trend to worse lesions in the extremes temperature groups: $\mathrm{G} 1\left(37^{\circ} \mathrm{C}\right)$ and $\mathrm{G} 4\left(4^{\circ} \mathrm{C}\right)$. Nevertheless, those findings did not achieve statistical significance, maybe due to the short time of reperfusion (acute experiment). The outcomes derived from TBARS analyses matched with the histopathologic results, since the TBARS had higher averages in all I/R groups compared to the control group.
As well as the tissue analyses, evaluation of TBARS revealed significant difference between the control group and the remaining groups. However the temperature had not interfered with the TBARS results. The significantly lesser value of TBARS when $\mathrm{I} / \mathrm{R}$ was not present is an evidence that free radicals production happened on the presence of $I / R$, because TBARS is a very sensible marker of lipid peroxidation of the cell membrane ${ }^{3}$. The most interesting outcome, however, came from the assessment of CAT, which is a quite important enzyme. This protein converts peroxide in water, leading to its inactivation ${ }^{11-16}$. On the presence of warm ischemia followed by reperfusion, the CAT usually rises in order to protect against the lipid peroxidation. When a protection factor is present concomitantly with $\mathrm{I} / \mathrm{R}$, as hypothermia, for instance, CAT cannot undergo an increment even in the presence of $I / R$, because the addition of cooling might dispense the antioxidant effect of CAT. Our data demonstrate that CAT has risen in G1 (warm I/R) in relation to G0 (control without I/R), and then CAT began to progressively fall soon as the temperature has been becoming lower. Therefore, the control group showed the basal level of CAT when I/R was not present. When warm ischemia was induced, CAT has increased. Nevertheless, on the presence of intense hypothermia $\left(\mathrm{G} 4,4^{\circ} \mathrm{C}\right)$ CAT has significantly decreased compared with the normothermic ischemic group (G1), with a $p<0.03$. These findings occurred due to the protection against lipid peroxidation offered by deep hypothermia, suggesting that the need of antioxidant's CAT proprieties during the period of $\mathrm{I} / \mathrm{R}$ were reduced. According to the results obtained for CAT, the target-temperature should be $4^{\circ} \mathrm{C}$ in order to obtain antioxidant effect. However, this statement did not have correspondence on histological examination (in four hours of reperfusion), maybe due to direct thermal damage against the renal tissue. Besides, there were no differences among the hypothermic groups relative to the CAT activity. SOD had no statistically significant difference among the groups. Interestingly the SOD had the onset of its decreasing on $\mathrm{G} 3\left(15^{\circ} \mathrm{C}\right)$ and the value went down until reach on $\mathrm{G} 4\left(4^{\circ} \mathrm{C}\right)$ with almost the same value found on $\mathrm{G0}$ (control). For $\mathrm{NO}_{2}, \mathrm{NO}_{3}$ (renal tissue) and F2IP (plasma), no significant difference was detected among the groups. Concluding, the results obtained suggest that the experimental model here presented was adequate to show the occurrence of histological changes derived from $\mathrm{I} / \mathrm{R}$ compared with controls. Moreover, this model was able to increase the release of TBARS when lipid peroxidation was present (under $\mathrm{I} / \mathrm{R})$. Another important conclusion is that the increased catalase during profound hypothermia $\left(4^{\circ} \mathrm{C}\right)$ suggests that this level of temperature is associated with higher antioxidative effect, although this temperature may cause direct thermal damage. 


\section{Conclusion}

This model of ischemia-reperfusion was efficient to produce oxidative-stress in the kidney, showing that $4^{\circ} \mathrm{C}$ offered significant decrease in free radicals production, although tissue protection was not observed.

\section{References}

1. Belzer FO, Southard JH. Principles of solid-organ preservation by cold storage. Transplantation. 1988;45(4):673-6.

2. Biberthaler P, Luchting B, Massberg S, Teusper D, Langer S, Leiderer R, Messmer K, Krombach F. The influence of organ temperature on hepatic ischemia-reperfusion injury: a systematic analysis. Transplantation. 2001;72(9):1486-90.

3. Behrends M, Hirose R, Serkova NJ, Coatney JL, Bedolli M, Yardi J, Park YH,Niemann CU. Mild hypothermia reduces the inflammatory response and hepatic ischemia/reperfusion injury in rats. Liver Int. 2006;26(6):734-41.

4. Tveita T, Johansen K, Lien AH, Myklebust R, Lindal S. Morphologic changes in tubular cells from in situ kidneys following experimental hypothermia and rewarming. APMIS. 2005;113(1):13-20.

5. Jablonski P, Howden BO, Rae DA, Birrel CS, Marshall VC, Tange J. An experimental model for assessment of renal recovery from warm ischemia. Transplantation. 1983;35(3):198-204.

6. Devarajan P. Update on mechanisms of ischemic acute kidney injury. J Am Soc Nephrol. 2006;17(6):1503-20.

7. Mangino MJ, Tian T, Ametani M, Lindell S, Southard JH Cytoskeletal involvement in hypothermic renal preservation injury. Transplantation. 2008;85(3):427-36.

8. Bartels-Stringer M, Kramers C, Wetzels JF, Russel FG, Groot HD, Rauen U. Hypothermia causes a marked injury to rat proximal tubular cells that is aggravated by all currently used preservation solutions. Cryobiology. 2003;47(1):82-91.

9. McCord JM. The superoxide free radical: its biochemistry and pathophysiology. Surgery. 1983;94(3):412-4.

10. Ahmad N, Hostert L, Pratt JR, Billar KJ, Potts DJ, Lodge JP. A pathophysiologic study of the kidney tubule to optimize organ preservation solutions. Kidney Int. 2004;66(1):77-90.

11. Halliwell B, Whiteman M. Measuring reactive species and oxidative damage in vivo and in cell culture: how should you do it and what do the results mean? Br J Pharmacol. 2004;142(2):231-55.

12. Vincent HK, Innes KE, Vincent KR. Oxidative stress and potential interventions to reduce oxidative stress in overweight and obesity. Diabetes Obes Metab. 2007;9(6):813-39.

13. Mayne ST. Antioxidant nutrients and chronic disease: use of biomarkers of exposure and oxidative stress status in epidemiologic research. J Nutr. 2003;133 Suppl 3, 933S-40S.

14. Huang D, Ou B, Prior RL. The chemistry behind antioxidant capacity assays. J Agric Food Chem. 2005;53(6):1841-56.

15. Halliwell B, Gutteridge J. Free radicals in biology and medicine. 4ed. New York: Oxford University Press, USA; 2007.

16. Bulkley GB. Free radical-mediated reperfusion injury: a selective review. Br J Cancer Suppl. 1987:8:66-73.

17. Grezzana Filho TJ, Mendonça TB, Gabiatti G, Rodrigues G, Marroni NA, Treis L, De Rossi SD, Corso CO. Topical hepatic hypothermia plus ischemic preconditioning: analysis of bile flow and ischemic injuries after initial reperfusion in rats. Acta Cir Bras. 2011;26(3):194-201.

18. Grezzana Filho TJ, Mendonça TB, Gabiatti G, Kruel CDP, Corso
CO. Topic liver hypothermia and ischemic preconditioning: a new model of ischemia and reperfusion in rats. Acta Cir Bras. 2009;24(4):262-6.

19. Grezzana Filho TJ, Corso CO, Zanotelli ML, Marroni CA, Brandão $\mathrm{AB}$, Schlindwein E, Leipnitz I, Meine MH, Fleck A Jr, Hoppen R, Kiss G, Cantisani GP. Liver glutathione depletion after preservation and reperfusion in human liver transplantation. Acta Cir Bras. 2006;21(4):223-9.

20. Misra HP, Fridovich I. The role of superoxide anion in the autoxidation of epinephrine and a simple assay for superoxide dismutase. J Biol Chem. 1972;247(10):3170-5.

\section{Acknowledgements}

To Marta Cioato, nurse from the Experimental Research Center (CPE); Vânia Naomi Hirakata, statistical counselor from the Group of Research and Post-Graduation; Department of Pathology and the Laboratory of Physiology and Experimental Hepatology.

\section{Correspondence: \\ Emanuel Burck dos Santos \\ Hospital de Clínicas de Porto Alegre \\ Serviço de Urologia \\ Rua Ramiro Barcelos, 2350 \\ 90035-903 Porto Alegre - RS Brasil \\ emanuelburck@yahoo.com}

\section{Received: April 10, 2013}

Review: June 12, 2013

Accepted: July 15, 2013

Conflict of interest: none

Financial sources: Incentive to Events and Research Fund-Porto Alegre Clinics Hospital (FIPE-HCPA).

${ }^{1}$ Research performed at Laboratory of Physiology and Experimental Pathology, Experimental Research Center (CPE), Porto Alegre Clinics Hospital (HCPA), Rio Grande do Sul Federal University (UFRGS), Porto Alegre-RS, Brazil. 